\title{
In Situ Analysis of the Thermal Evolution of Electrodeposited Fe-C Coatings
}

\author{
Nielsen, Jacob Obitsø; Christiansen, Thomas Lundin; Pantleon, Karen
}

Published in:

Metallurgical and Materials Transactions A: Physical Metallurgy and Materials Science

Link to article, DOI:

10.1007/s11661-020-05904-z

Publication date:

2020

Document Version

Peer reviewed version

Link back to DTU Orbit

Citation (APA):

Nielsen, J. O., Christiansen, T. L., \& Pantleon, K. (2020). In Situ Analysis of the Thermal Evolution of Electrodeposited Fe-C Coatings. Metallurgical and Materials Transactions A: Physical Metallurgy and Materials Science, 51(9), 4880-4889. https://doi.org/10.1007/s11661-020-05904-z

\section{General rights}

Copyright and moral rights for the publications made accessible in the public portal are retained by the authors and/or other copyright owners and it is a condition of accessing publications that users recognise and abide by the legal requirements associated with these rights.

- Users may download and print one copy of any publication from the public portal for the purpose of private study or research.

- You may not further distribute the material or use it for any profit-making activity or commercial gain

- You may freely distribute the URL identifying the publication in the public portal 


\section{In-situ analysis of the thermal evolution of 2 electrodeposited Fe-C coatings}

3 Jacob Obitsø Nielsen, Thomas Lundin Christiansen, Karen Pantleon*

4 Technical University of Denmark, Department of Mechanical Engineering, Produktionstorvet,

5 building 425, DK - 2800 Kongens Lyngby, Denmark

$6 \quad *$ Corresponding author: kapa@mek.dtu.dk

7 Abstract

8 Fe-C coatings with a high amount of carbon were electrodeposited from an iron-sulfate

9 electrolyte. Citric acid as an additive in the electrolyte, not only served as carbon source during

10 electrodeposition, but also caused the reproducible co-deposition of oxygen and hydrogen. The

11 various co-deposited elements $(\mathrm{C}, \mathrm{O}, \mathrm{H})$ result in a complex nature of the as-deposited coatings

12 and allow for deliberate alterations of the coating properties by post-deposition annealing. The

13 thermal evolution of electrodeposited Fe-C coatings was investigated in-situ during isochronal

14 annealing. In-situ synchrotron diffraction analysis revealed temperature dependent phase

15 transformations, which was supplemented with in-situ thermal analysis for investigating the

16 evolution of co-deposited elements and associated mass changes during annealing. Based on the

17 determined activation energies of identified thermal events, the underlying mechanisms are

18 discussed. The results clearly indicate the role of co-deposited elements in the coatings and

19 suggest that they partly exist in form of organic compounds, which decompose during annealing.

20 In addition to revealing the thermal stability of the coatings and quantifying the coating's thermal

21 evolution, the complementary methods of in-situ analysis considerably improved the

22 understanding of the as-deposited $\mathrm{Fe}-\mathrm{C}$ coatings - both are essential prerequisites for the

23 successful application of the Fe-C coatings.

\section{Keywords}

25 electrodeposition, annealing, phase transformations, thermal analysis, synchrotron diffraction. 
The electrodeposition of iron and carbon (Fe-C) coatings implies a number of advantages for improving the hardness and wear resistance of surfaces. The deposition process is commercially feasible in industry. It bases on an inexpensive and environmentally friendly electrolyte and it allows the straightforward deposition of Fe-C coatings with thicknesses up to several hundreds of micrometers. Moreover, excellent mechanical properties are consistently reported for asdeposited Fe-C coatings [1-7]. In particular the ability of producing very hard coatings with microhardness values as high as for hardened steels makes the electrodeposited Fe-C coatings very attractive for various engineering applications where high hardness and good wear resistance are important. This entails both the dedicated electrodeposition of Fe- $\mathrm{C}$ coatings as a final process in the fabrication of components and the repair of worn or damaged surfaces by site-specific repeated deposition. In addition to the application of $\mathrm{Fe}-\mathrm{C}$ coatings in their asdeposited state, a further potential for surface engineering is provided by the chemical nature of the coatings. The co-deposited carbon and other elements, like oxygen and hydrogen originating from the applied electrolyte, play a decisive role during post-deposition heat treatments, whereby the as-deposited microstructure can be deliberately altered [4,5,7-9]. Thermal treatment of the electrodeposited Fe-C coatings, which already in their as-deposited state are fairly hard with about $800 \mathrm{HV}[6,7]$ is associated with a further hardness increase of up to $1300 \mathrm{HV}$ [7]. Hence, from an application point of view, the mechanical properties are very convincing and pave the way for a number of applications of Fe-C coatings. From a scientific point of view, thorough understanding of the as-deposited microstructure has hitherto not been obtained and despite good reproducibility of the electrodeposition process with consistent results in literature, the nature of as-deposited Fe-C coatings and the role of the co-deposited carbon are subject of different interpretations.

51 Previous studies of Fe-C coatings refer to an iron-sulfate electrolyte, which was optimized to resist the oxidation of $\mathrm{Fe}^{2+}$ to $\mathrm{Fe}^{3+}$ by the addition of a carboxylic acid that also acts as a buffer,

53 carbon source and complexing agent $[5,10]$. The composition and functional groups of the

54 carboxylic acid have been found to influence the amount of co-deposited carbon, the morphology

55 and the associated properties of the Fe-C coatings [2,3,5,11-14]. In addition, the applied

56 electrodeposition conditions, like the cathode current density, the $\mathrm{pH}$ value and the temperature 
57 of the electrolyte $[2,3,5,15]$, influence the current efficiency and, hence, the chemical

58 composition, microstructure and properties of the as-deposited coatings. Typically, the

59 electrodeposited Fe-C coatings contain high concentrations of carbon up to about $1 \mathrm{wt} \%$. Such

60 high amount of carbon considerably exceeds the solubility of carbon in iron at room temperature,

61 which, typically for Fe-C alloys, suggests either the formation of iron carbides or the presence of

62 carbon in supersaturated solid solution in the iron lattice. Previous investigations of

63 electrodeposited Fe-C coatings by means of diffraction analysis consistently revealed the

64 presence of one major phase in as-deposited coatings, which is interpreted either as ferrite (not

65 containing carbon in thermodynamic equilibrium) [5-7,13] or as martensite (with carbon in

66 supersaturated solid solution) $[2,3,11,12,15]$. The similarity of both lattices and the strong

67 crystallographic texture of as-deposited Fe-C coatings complicate the phase analysis. The

68 presence of a supersaturated solid solution would provide an immediate explanation for the

69 location of carbon in the coatings, i.e. carbon would be interstitially dissolved. However, the

70 very high measured carbon concentration would need to result in enormous changes of the iron

71 lattice and this should cause either very broad and shifted diffraction peaks or asymmetric and

72 even split diffraction peaks (apparently, both observations are reported). On the other hand, in

73 case of ferrite without any carbon in its bcc lattice, the nature of the measured high amount of

74 carbon would require the presence of a second phase in as-deposited Fe-C coatings. Indeed,

75 diffraction analysis repeatedly revealed a second phase, but thorough phase identification is

76 considerably hindered by the limited number of peaks; in addition to $\alpha$-Fe, only one further peak

77 is clearly evident [4-7] with only low diffracted intensities. As a consequence, phase analysis has

78 not yet been unambiguous. As an attempt to clarify the location of the measured carbon, this

79 second phase in the as-deposited $\mathrm{Fe}-\mathrm{C}$ coatings has previously been explained as $\mathrm{Fe}_{2} \mathrm{C}$ transition

80 carbides $[4,8,9]$, but alternative explanations including other co-deposited elements are possible

81 [7]. The ambiguity of phase analysis based on the single additional peak, which consistently

82 corresponds to a lattice spacing of $d=0.237 \mathrm{~nm}$, is reflected in its present terminology as

83 "nameless" peak referring to the not yet identified, "nameless", phase in the as-deposited Fe-C

84 coatings. A recent $e x$-situ isothermal annealing study revealed that this phase is present up to a

85 temperature of about $300{ }^{\circ} \mathrm{C}[4,7,8]$. Tracing the evolution of this phase by an in-situ annealing

86 study and investigating the occurrence of further phase transformations is the purpose of the

87 present work. 
88 The thermal stability of Fe-C coatings with a high carbon content of $0.88 \pm 0.02$ wt $\%$ is followed in-situ during isochronal annealing from room temperature to above the austenitization

90 temperature. The occurring phase transformations are revealed by in-situ diffraction analysis and

91 discussed in relation to the evolution of co-deposited elements and associated mass changes

92 obtained from in-situ thermogravimetric analysis in combination with mass spectroscopy.

\section{2. Method}

\subsection{Electrodeposition of Fe-C coatings}

96 The electrolyte was prepared from chemicals of analytical grade with a concentration of 0.143

$97 \mathrm{~mol} / \mathrm{dm}^{3}$ iron (II) sulfate heptahydrate, $6.2 \times 10^{-3} \mathrm{~mol} / \mathrm{dm}^{3}$ citric acid monohydrate and deionized

98 water. A 10 Liter electrolyte was used to minimize the change in chemical composition of the

99 electrolyte during deposition. The electrolyte temperature was kept at $50^{\circ} \mathrm{C}$ and mechanical

100 stirring was applied during deposition. The $\mathrm{pH}$-value of the electrolyte was controlled during

101 deposition and maintained between 2.5 and 2.8 using a $\mathrm{H}_{2} \mathrm{SO}_{4}$-diluted solution. An interstitial-

102 free steel plate was used as anode. The applied deposition parameters represent the previously

103 optimized conditions and they result in coatings with a carbon content of $0.88 \pm 0.02 \mathrm{wt} \%$ [6].

104 The cathode consisted of a $10 \times 9 \mathrm{~cm}$ low carbon steel plate covered with a conductive lead tape,

105 such that deposition occurred both on lead and on the steel substrate simultaneously. The

106 backside of the cathode was covered with an isolating electrolyte-resistant tape to ensure that

107 only the side towards the anode was deposited. Prior to electrodeposition, the cathode was pre-

108 treated by 2 min cathodic degreasing at $5 \mathrm{~V}$ followed by 2 min activation in commercial dry acid

109629 SV from EngTech Scandinavia. Electrodeposition was carried out at a constant current

110 density of $3.0 \mathrm{~A} / \mathrm{dm}^{2}$ applied for 15 hours resulting in $360 \mu \mathrm{m}$ thick Fe-C coatings. The Fe-C

111 coatings were immediately after deposition rinsed in water, then rinsed in ethanol and carefully

112 dried to avoid oxidation. The Fe-C coatings were protected from any contact with oxidizing

113 environments during storage.

114 The abovementioned design of the cathode ensured that multiple identical samples were obtained

115 from the same deposition event, in which the substrate (lead or low carbon steel) is unimportant

116 for the finally $360 \mu \mathrm{m}$ thick Fe-C coatings, but allows to obtain dedicated samples for annealing. 
117 Due to low adhesion of the Fe-C coatings on the lead tape, the coating could easily be detached

118 from the tape, thus providing free-standing coatings. They were used for in-situ thermal analysis, 119 where it was essential to quantify the chemical species that evolved in the coating material. The

120 Fe-C coatings on low carbon steel allowed better sample handling for in-situ diffraction analysis

121 during annealing. The various sample pieces used for the present study were collected at least 1

$122 \mathrm{~cm}$ away from the edge of the electrodeposited plate to avoid any potential edge effect from

123 electrodeposition.

\section{$124 \quad 2.2$ In-situ annealing experiments}

\subsubsection{Synchrotron diffraction}

126 Energy-dispersive diffraction (EDD) was performed in-situ at the synchrotron facility BESSY II 127 at the EDDI beamline. In EDD, a white X-ray beam with a continuous photon energy spectrum is 128 used at a fixed diffraction angle $2 \theta$, and diffraction occurs for crystallographic lattice planes with 129 spacing $\mathrm{d}_{\mathrm{hkl}}$ at a photon energy $\mathrm{E}_{\mathrm{hkl}}$ according to [16]

$$
E_{h k l}=\frac{h c}{2 \sin \theta} \cdot \frac{1}{d_{h k l}}
$$

131 where $h$ is Planck's constant and $c$ is the speed of light.

132 Compared to angle dispersive diffraction, the EDD mode has significant advantages, in particular

133 for time- and/or temperature-resolved in-situ measurements. Complete diffraction patterns with a 134 multitude of diffraction lines, $\mathrm{E}_{\mathrm{hkl}}$, are recorded simultaneously under fixed geometrical

135 conditions, i.e. without scanning the $2 \theta$ angle. In addition, the very intense synchrotron radiation 136 allows for short recording times for a complete diffraction pattern with good counting statistic.

137 Owing to the different photon energies, the structural information contained in each diffraction

138 line at the energy $E_{h k l}$ has to be assigned to different average information depths [16]. For the 139 applied symmetric diffraction geometry and a diffraction angle of $2 \theta=8^{\circ}$, for example, the 211 140 reflection of iron corresponds to an information depth of about $67 \mu \mathrm{m}$.

141 In-situ annealing experiments during EDD analysis were performed in an Anton Paar DHS 1100 142 Domed Hot Stage under continuous flow of inert argon gas (99.999 mol \% purity) at a constant 
143 pressure of 1.4 bar. As-deposited Fe-C coatings on the low carbon steel substrate, were placed on 144 the heating element (alumina plate) onto which they were mounted by mild clamping. The

145 temperature was measured with a Pt-Pt10Rh thermocouple fixed to the stage. Isochronal

146 annealing was performed from $30{ }^{\circ} \mathrm{C}$ to $800{ }^{\circ} \mathrm{C}$ using a heating rate of $2 \mathrm{~K} / \mathrm{min}$ and an

147 acquisition time of 30 seconds per EDD spectrum, resulting in a high resolution of one

148 diffraction pattern per Kelvin. For qualitative phase analysis, the diffraction lines were fitted

149 with pseudo-Voigt profile functions. A gold reference standard was used for calibration of the

150 energy offset. The peak position was corrected for thermal expansion using the linear thermal

151 expansion coefficient for ferrite of $\alpha=15.1\left(10^{-6} \mathrm{~K}^{-1}\right)$, which was obtained for the present

152 samples from their EDD spectra measured during cooling from $800{ }^{\circ} \mathrm{C}$ to room temperature

153 after isochronal annealing.

\section{$154 \quad$ 2.2.2 Thermal analysis}

155 Simultaneous thermogravimetry (TGA) and differential thermal analysis (DTA) were performed

156 in a Netzsch STA 449F3 coupled with a Netzsch QMS 403 Aëolos quadrupole mass

157 spectrometer (MS). The setup enables the detection and identification of evolved gases in time

158 correlation with enthalpy and mass changes. For each measurement, a substrate-free coating

159 weighing about $250 \mathrm{mg}$ was placed in an alumina crucible. The sample chamber was pumped to

160 vacuum and flushed with argon three times prior to each measurement. Heating was carried out

161 in an inert atmosphere created by flowing argon gas (99.999 mol \% purity) through the chamber

162 with a rate of $30 \mathrm{~mL} / \mathrm{min}$.

163 A sample was subjected to three cycles of isochronal heating from $40{ }^{\circ} \mathrm{C}$ to $1000{ }^{\circ} \mathrm{C}$ using a

164 heating rate of $2 \mathrm{~K} / \mathrm{min}$. Before the thermogravimetric analysis and in between the sequential

165 heating cycles, the sample was hold for 2 hours at $40{ }^{\circ} \mathrm{C}$ to ensure a stable and consistent

166 environment. The cooling rate was set to $40 \mathrm{~K} / \mathrm{min}$. The first and second isochronal annealing

167 were adjusted for instrumental background by using the second and third isochronal annealing,

168 respectively.

169 From isochronal annealing experiments applying different heating rates, the activation energies

170 for thermal events measured by DTA were evaluated by means of a Kissinger analysis applying 
171 different heating rates [17]. For each thermal event, the activation energy was determined from

172 the slope of the straight line obtained by plotting $\ln \left(\mathrm{T}_{\mathrm{f}}^{2} / \Phi\right)$ versus $1 / \mathrm{T}_{\mathrm{f}}$, where $\Phi$ corresponds to

173 the applied constant heating rates of $2 \mathrm{~K} / \mathrm{min}, 10 \mathrm{~K} / \mathrm{min}, 20 \mathrm{~K} / \mathrm{min}$ and $40 \mathrm{~K} / \mathrm{min}$, respectively.

$174 \mathrm{~T}_{\mathrm{f}}$ corresponds to a fixed stage of transformation $\mathrm{f}^{\prime}$ measured for the various heating rates. The

175 values for $\mathrm{T}_{\mathrm{f}}$, refer to the maxima of exothermic peaks, which were determined by fitting a

176 Gaussian function to the background subtracted peaks.

\section{Results}

\subsection{Diffraction analysis}

180 In-situ diffraction analysis during isochronal annealing of an as-deposited $\mathrm{Fe}-\mathrm{C}$ coating using a

181 heating rate of $2 \mathrm{~K} / \mathrm{min}$ revealed the as-deposited phases, along with the temperature induced 182 phase transformations from room temperature to above the austenitization temperature. Figure 1 183 shows the acquired EDD spectra with high temperature resolution (one diffraction spectrum per 184 Kelvin) as a contour plot.

185 The as-deposited coating mainly consists of $\alpha$-Fe (JCPDS 6-696). According to the strong <311> 186 fiber texture of the as-deposited Fe-C coating [6], only the 110 and 211 reflections of $\alpha$-iron are 187 detected, while the 200 reflection is absent. The strain-free lattice spacings $\mathrm{d}_{0}$ for the 110 and

188211 reflections of $\alpha$-Fe were determined for the as-deposited coating by tilting the sample 189 around the strain-free direction $\left(\psi_{0}=41.16^{\circ}\right)$, providing $\mathrm{d}_{0 \_} 110=0.20273 \mathrm{~nm}$ and $\mathrm{d}_{0 \_211}=$

$190 \quad 0.11706 \mathrm{~nm}$, respectively. Both d-spacings match the corresponding values for carbon-free $\alpha$-Fe

191 (JCPDS 6-696 with $\mathrm{d}_{110}=0.20269 \mathrm{~nm}$ and $\mathrm{d}_{211}=0.11702 \mathrm{~nm}$ ), which indicates that carbon-free

192 bcc ferrite is present in the as-deposited coating. The measured peaks are broadened

193 corresponding to the nanocrystalline nature of the coating, which previously has been quantified

194 with an average crystallite size of 15-40 $\mathrm{nm}$ [7]. Apart from ferrite, only one additional peak is

195 detected in the as-deposited coating, namely at $37.5 \mathrm{keV}$ (cf. Figure 1). This peak corresponds

196 to a d-spacing of $0.237 \mathrm{~nm}$. It has been previously reported from conventional laboratory X-ray

197 diffraction phase analysis [4-6,8], but, as mentioned above, no clear phase identification is 
198 possible based on that single peak only and, therefore, in the following, it is referred to as the 199 "nameless phase".

200 During annealing, a sudden drop of the intensity of all peaks was observed at around $100{ }^{\circ} \mathrm{C}$.

201 After careful consideration and exclusion of any experimental reason for this intensity drop, the 202 only explanation is a sudden change of the sample height (related to the occurring evolution of 203 the coating with temperature, as discussed later in this manuscript) and accordingly, the sample 204 was repositioned by adjusting the stage height. This is reflected in slight fluctuations of the 205 diffracted intensities in Figure 1 until they stabilized at around $144^{\circ} \mathrm{C}$. At that temperature, still 206 only $\alpha-F e$ and the "nameless phase" are present.

207 With continued heating, the formation of magnetite $\mathrm{Fe}_{3} \mathrm{O}_{4}$ (JCPDS 76-0957) is detected at about $208259{ }^{\circ} \mathrm{C}$ and cementite $\mathrm{Fe}_{3} \mathrm{C}$ (JCPDS 77-0255) forms at about $310{ }^{\circ} \mathrm{C}$ (cf. Figure 1). The 209 formation of both phases confirms the presence of oxygen and carbon in the as-deposited 210 coating, which are known to be co-deposited during electrochemical deposition [6], although the 211 nature and location of these light elements in the as-deposited coatings could not be clarified yet.

212 The formation of magnetite and cementite, as revealed during in-situ annealing in the present 213 study, is consistent with previous ex-situ observations after isothermal furnace annealing of $\mathrm{Fe}-\mathrm{C}$ 214 coatings [7].

215 With increasing temperature, the precipitation of magnetite and cementite proceeds as indicated 216 by continuously increasing intensities of their corresponding diffraction peaks (cf. Figure 1). A 217 remarkable change is observed at a temperature of $328^{\circ} \mathrm{C}$, which seems to be related to the 218 transformation of the "nameless" phase. The intensity of its corresponding peak at $37.5 \mathrm{keV}$ 219 drops suddenly and the peak finally disappears, while at the same time a new peak develops near 220 the original one. The partly overlapping intensities of the "nameless" peak and the new one cause 221 some asymmetry of the measured peak profile. This hinders accurate peak fitting at this 222 temperature and, therefore, the intensity decrease of the "nameless" peak and the corresponding 223 transformation temperature of the "nameless phase" cannot be quantified precisely. In 224 accordance with a further evolution of cementite $\mathrm{Fe}_{3} \mathrm{C}$, the newly arising peak originates from $225 \mathrm{Fe}_{3} \mathrm{C}$. At about the same temperature of the disappearance of the single peak related to the 226 "nameless phase", another observation from the diffraction results is of interest. Again, similarly 
227 as observed at about $100{ }^{\circ} \mathrm{C}$, as mentioned above, changes of the sample height and associated 228 intensity changes of all peaks were recorded and required repositioning of the sample by 229 readjusting the stage height (also this observation is related to the evolution of the coating and 230 will be discussed together with results from the thermal analysis later in this manuscript).

231 At a temperature of about $571{ }^{\circ} \mathrm{C}$, the transformation of $\mathrm{Fe}_{3} \mathrm{O}_{4}$ to wüstite $\mathrm{FeO}$ (JCPDS 77-2355) 232 occurs (cf. Figure 1). Finally, at about $727^{\circ} \mathrm{C}$, the phase transformation from $\alpha$-Fe ferrite to $\gamma$-Fe 233 austenite (JCPDS 31-0619) occurred and, simultaneously, the peaks corresponding to $\mathrm{Fe}_{3} \mathrm{C}$ drop 234 in intensity, because carbides dissolve and carbon goes into solid solution in austenite. Peaks 235 corresponding to $\mathrm{FeO}$ are still present above the austenitization temperature.

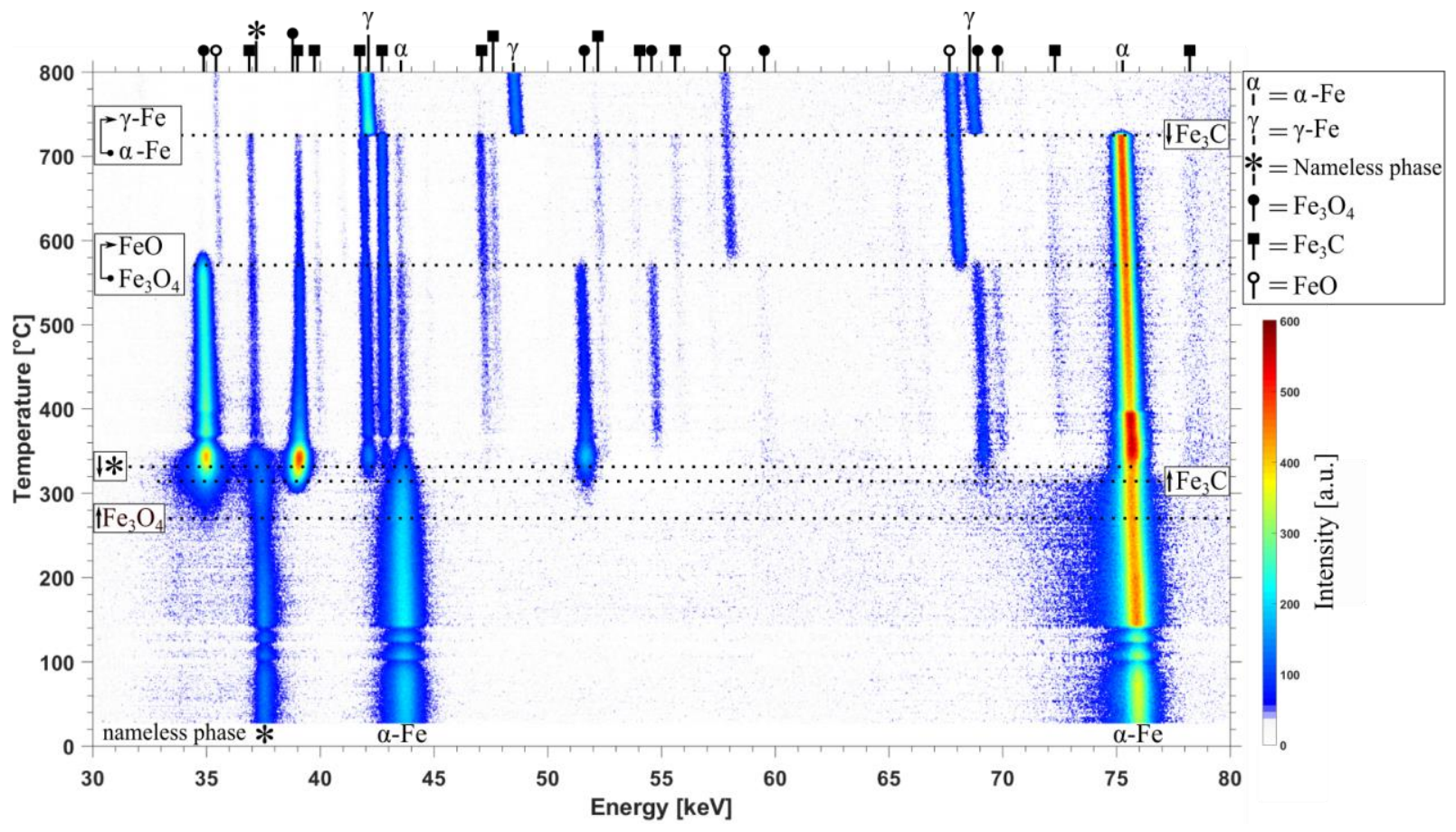

237 Figure 1: Synchrotron energy-dispersive diffraction spectra of in-situ annealing of an as238 deposited Fe-C coating using a heating rate of $2 \mathrm{~K} / \mathrm{min}$ from 30 to $800{ }^{\circ} \mathrm{C}$. 


\subsubsection{Thermogravimetry, differential thermal analysis and mass spectrometry}

244 The in-situ isochronal annealing by simultaneous DTA and TGA coupled with MS, using a 245 heating rate of $2 \mathrm{~K} / \mathrm{min}$ (i.e. the same as applied during in-situ diffraction analysis), revealed 246 further information on the thermal stability of the as-deposited Fe-C coating. The results in 247 Figure $2 \mathrm{a}$ and $2 \mathrm{~b}$ correspond to the first annealing to $1000{ }^{\circ} \mathrm{C}$ and the subsequent annealing of 248 the same sample to $1000{ }^{\circ} \mathrm{C}$, respectively. The signals recorded by MS have been correlated to 249 the individual elements using their ion mass. The measured species involved $\mathrm{H}_{2}{ }^{+}, \mathrm{O}_{2}{ }^{+}$and $\mathrm{CO}_{2}{ }^{+}$ 250 having a mass/charge ratio of $2 \mathrm{amu}, 32 \mathrm{amu}$ and $44 \mathrm{amu}$, respectively. Although the 251 measurement was carried out in an inert Ar atmosphere, a low concentration of impurities in the 252 gas such as $\mathrm{O}_{2}$ and $\mathrm{H}_{2}$ is seen as background in the beginning of the experiment. An increase in 253 the DTA signal in Figure 2 relates to an exothermic reaction and a decrease indicates an 254 endothermic reaction.

255 The first annealing cycle to $1000{ }^{\circ} \mathrm{C}$ (cf. Figure 2a) shows a mass loss just prior to an exothermic 256 reaction at about $114{ }^{\circ} \mathrm{C}$. The relatively low temperature and the increase in intensities of $\mathrm{H}_{2}$ 257 suggest that the reaction is related to dehydrogenation of absorbed hydrogen trapped in the as258 deposited coating, which is a typical phenomenon during electrodeposition. This hydrogen 259 originates from electrolysis at the cathode surface and results in a current efficiency of the 260 deposition process below 100\% (in fact, a current efficiency of only $60 \%$ applies for the present 261 deposition [7]). The simultaneous decrease in $\mathrm{O}_{2}$ is likely related to its reaction with the desorbed $262 \mathrm{H}_{2}$ from the sample and the corresponding formation of $\mathrm{H}_{2} \mathrm{O}$ before reaching the MS detector.

263 Energy is removed from the system in the temperature range following the exothermic reaction 264 at $114^{\circ} \mathrm{C}$, which is interpreted as hydrogen desorption.

265 At around $250{ }^{\circ} \mathrm{C}$, an increase in $\mathrm{CO}_{2}$ is detected, but at this temperature neither the DTA signal 266 nor the mass loss gradient change.

267 At $310^{\circ} \mathrm{C}$, a relatively small exothermic peak is measured and directly followed by a more 268 pronounced exothermic peak of much higher intensity with a maximum at $360^{\circ} \mathrm{C}$. These 269 exothermic reactions are accompanied by a small increase in $\mathrm{O}_{2}$ and $\mathrm{CO}_{2}$ at around $340{ }^{\circ} \mathrm{C}$ along 
270 with a change in the mass loss gradient. Simultaneously, the intensity of $\mathrm{H}_{2}$ increases

271 significantly and reveals a maximum at $375^{\circ} \mathrm{C}$. The associated desorption of hydrogen continues

272 until a temperature of around $436{ }^{\circ} \mathrm{C}$ is reached. Energy is removed from the system in the

273 temperature range following the exothermic reaction at $360{ }^{\circ} \mathrm{C}$, which is interpreted as hydrogen

274 desorption.

275 A relatively small exothermic peak is measured at $505^{\circ} \mathrm{C}$, without a notable change in the TGA

276 or MS signals. An endothermic peak at $570{ }^{\circ} \mathrm{C}$ indicates the phase transformation of $\mathrm{Fe}_{3} \mathrm{O}_{4}$ to

$277 \mathrm{FeO}$, in accordance with diffraction analysis (cf. Figure 1). At the same temperature, a change in

278 intensity for $\mathrm{CO}_{2}$ is measured, along with an increased mass loss, which is related to

279 decarburization. At $705^{\circ} \mathrm{C}$ a small peak in the $\mathrm{CO}_{2}$ intensity is measured, which is followed by a

280 pronounced endothermic peak at $725^{\circ} \mathrm{C}$ corresponding to the austenitization temperature, thus,

281 the transformation of $\alpha$-Fe ferrite to $\gamma$-Fe austenite.

282 The second heating cycle to $1000{ }^{\circ} \mathrm{C}$ (cf. Figure $2 \mathrm{~b}$ ) reveals an exothermic peak at $295^{\circ} \mathrm{C}$ and

283 endothermic peaks at $585^{\circ} \mathrm{C}$ and $725^{\circ} \mathrm{C}$ corresponding to the phase transformation of $\mathrm{FeO}$

284 (which is still present after the first heating cycle) to $\mathrm{Fe}_{3} \mathrm{O}_{4}$, the phase transformation of $\mathrm{Fe}_{3} \mathrm{O}_{4}$ to

$285 \mathrm{FeO}$ and the formation of austenite, respectively. There is no apparent mass change, before

286 decarburization is measured by an increased intensity for $\mathrm{CO}_{2}$ at around $590{ }^{\circ} \mathrm{C}$.

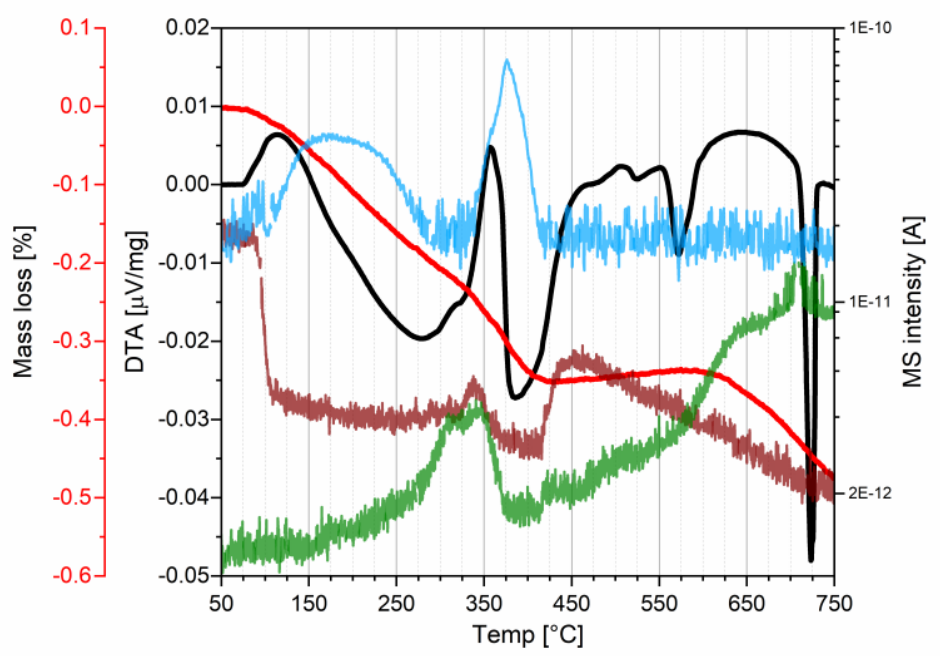

$287 \quad$ a)

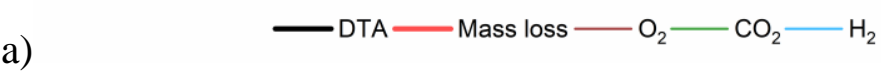




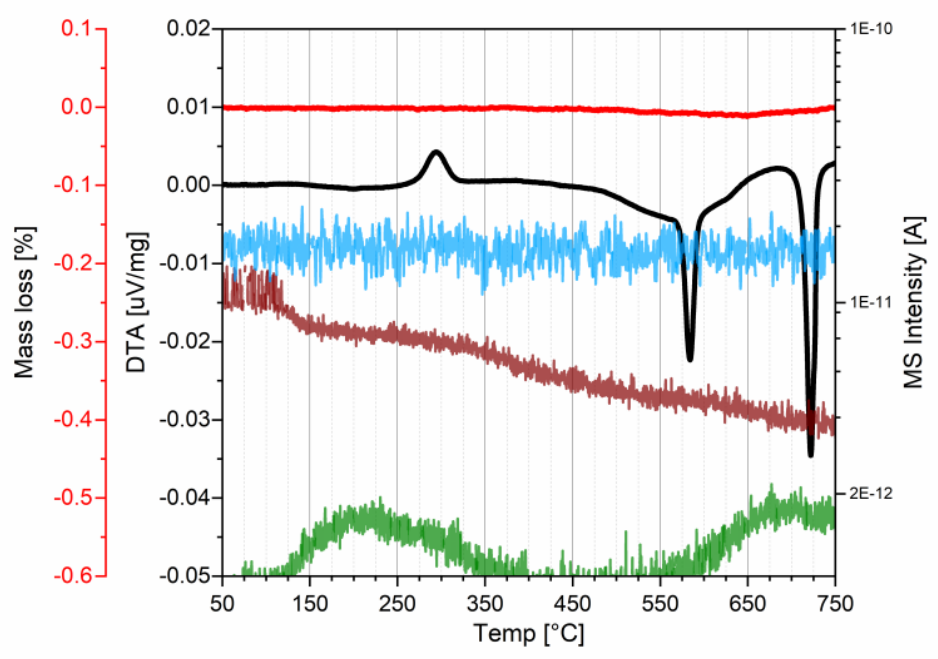

b)

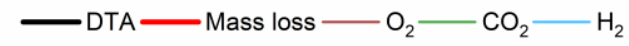

289 Figure 2: Simultaneous thermogravimetry, differential thermal analysis and mass spectrometry to

290 detect and identify thermal events, in correlation to the evaporated gases. The black left axis

291 corresponds to the DTA signal and the red left axis corresponds to the measured mass loss. The

292 right axis corresponds to the various desorbed gasses measured by MS. Figure 2a refers to the

293 first annealing cycle and Figure $2 \mathrm{~b}$ reflects the second annealing cycle of the same coating. The

294 applied heating rate corresponds to $2 \mathrm{~K} / \mathrm{min}$.

\subsubsection{Determination of activation energies}

296 Applying different heating rates for isochronal annealing of as-deposited Fe-C coatings (similar

297 to the example shown for $2 \mathrm{~K} / \mathrm{min}$ in Figure 2a), three separate thermal events are recorded as

298 exothermic peaks by DTA in the temperature range up to $500{ }^{\circ} \mathrm{C}$, which is shown in Figure $3 \mathrm{a}$.

299 The heating rate affects both the temperatures of the occurring thermal events and their

300 corresponding intensities in the DTA curves: with increasing heating rate, the peak temperature

301 and the recorded intensities increase. The corresponding Kissinger plot in Figure $3 \mathrm{~b}$ provides the

302 activation energies of the three thermal events. The relatively small exothermic peak measured at

$303310{ }^{\circ} \mathrm{C}$ for $2 \mathrm{~K} / \mathrm{min}$ (and correspondingly higher temperatures for increased heating rates, cf.

304 Figure 3a) is not included in the Kissinger analysis as it overlaps with the exothermic peak of

305 much higher intensity, which hinders an accurate peak fit. The thermal events relate to the

306 desorbed gasses measured by MS, as explained below. 
307 The first thermal event (at around $114^{\circ} \mathrm{C}$ for $\Phi=2 \mathrm{~K} / \mathrm{min}$ ) corresponds to dehydrogenation,

308 where the co-deposited hydrogen originating from electrolysis at the cathode surface (see above)

309 is released from the sample. The calculated activation energy of this first thermal event amounts

310 to $40 \mathrm{~kJ} / \mathrm{mol}$.

311 The second thermal event is indicated by an exothermic peak (at around $284{ }^{\circ} \mathrm{C}$ for $\Phi=10$

$312 \mathrm{~K} / \mathrm{min}$ ) and corresponds to an activation energy of $98 \mathrm{~kJ} / \mathrm{mol}$. For the low heating rate of 2

$313 \mathrm{~K} / \mathrm{min}$ the second thermal event cannot be verified experimentally due to too low peak intensity

314 (cf. Figure 3a) and therefore it cannot be related to the desorbed elements according to Figure 2a.

315 The third thermal event (at $360{ }^{\circ} \mathrm{C}$ for $\Phi=2 \mathrm{~K} / \mathrm{min}$ ) was clearly detected by its exothermic peak

316 for all heating rates and corresponds to an activation energy of $151 \mathrm{~kJ} / \mathrm{mol}$. This event is

317 characterized as a thermal decomposition, which relates to a mass loss, an enthalphy change and

318 the release of $\mathrm{H}_{2}$ (cf. Figure 2a). Furthermore, the increased intensities of $\mathrm{O}_{2}$ and $\mathrm{CO}_{2}$ measured

319 at $340{ }^{\circ} \mathrm{C}$ (cf. Figure 2a) suggest that also carbon and oxygen are released during this third

320 thermal event.

321
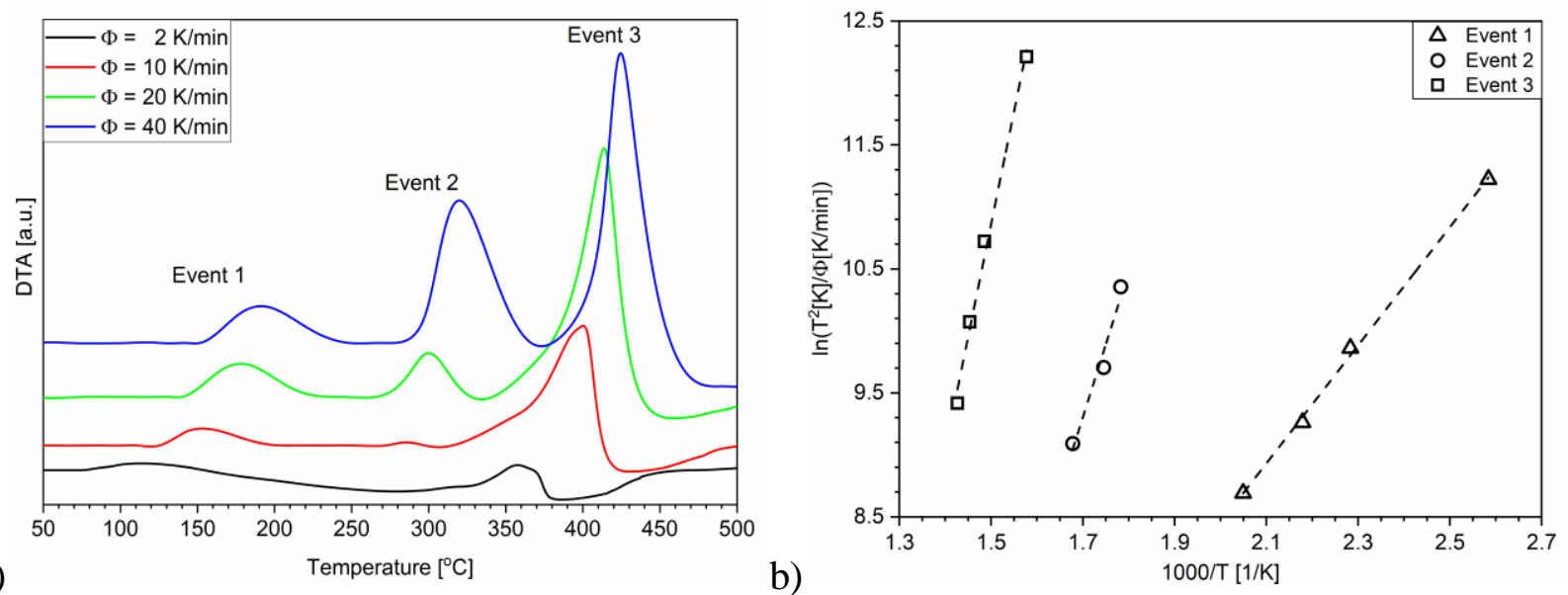

322 Figure 3: Isochronal Kissinger analysis (a) differential thermal analysis during isochronal

323 annealing of an as-deposited sample applying heating rates of 2, 10, 20 and $40 \mathrm{~K} / \mathrm{min}$ (b)

324 Kissinger plot for different thermal events measured for isochronal annealing with heating rates 325 of $2,10,20$ and $40 \mathrm{~K} / \mathrm{min}$. 


\section{Discussion}

328 For the present samples, carbon-free ferrite is clearly detected as the major phase in as-deposited 329 coatings, but XRD also indicates an additional crystalline phase, which cannot be identified from 330 the measured single peak and therefore, so far, is called the "nameless phase". As an approach to 331 discover the nature of this phase, synchrotron diffraction has been carried out also in

332 transmission and under various sample tilts and rotations (not shown here), but no additional 333 reflections could be revealed. The applied in-situ analysis during isochronal annealing by means 334 of energy-dispersive synchrotron diffraction allows tracing the occurring phase transformations 335 with an excellent temperature resolution. Although such in-situ diffraction analysis provides the 336 thermal stability of the electrodeposited Fe-C coatings and supports an interpretation of the as337 deposited nature of the coatings, in fact, it only can detect crystalline phases. The combination of 338 in-situ diffraction analysis with in-situ thermal analysis for the same as-deposited Fe-C coatings, as in the present work, supports the interpretation by cross-linking with the temperature-

340 dependent evolution of co-deposited elements (carbon, oxygen, hydrogen) during annealing. The 341 complementary results obtained from both methods of in-situ analysis provide the following 342 interpretation of the thermal stability of Fe-C coatings and, based on the coating's thermal 343 evolution, conclusions regarding the as-deposited Fe-C coatings can be drawn, as discussed in 344 the following. The specific temperatures stated in the discussion refer to the data obtained for in345 situ isochronal annealing experiments using a heating rate of $2 \mathrm{~K} / \mathrm{min}$ unless otherwise noted.

\subsection{Low temperature range - below $200{ }^{\circ} \mathrm{C}$}

347 Already at a relatively low temperature of about $114^{\circ} \mathrm{C}$, co-deposited hydrogen desorbs from the 348 coating (cf. Figure 2a). This confirms that hydrogen indeed is present in as-deposited coatings, 349 which previously has been suggested from chemical analysis (although hydrogen could not be 350 quantified [6,7]) and is reflected in a low current efficiency of only $60.5 \%$ for the applied 351 deposition process. The determined activation energy of $40 \mathrm{~kJ} / \mathrm{mol}$ for this first thermal event 352 indicates that this hydrogen, which originates from electrolysis at the cathode during deposition, 353 has been trapped in either microvoids or grain boundaries, for which trap activation energies for 354 hydrogen evolution of $35.15 \mathrm{~kJ} / \mathrm{mol}$ or $17.2 \mathrm{~kJ} / \mathrm{mol}$ [18], respectively, are reported for pure iron. 355 The nanocrystalline microstructure of the as-deposited Fe-C coating [6,7] provides a high 
number of grain boundaries for trapping and the reported temperature of hydrogen evolution

357 from grain boundaries $\left(105^{\circ} \mathrm{C}\right.$ for a heating rate of $3.06 \mathrm{~K} / \mathrm{min}$ [18]) agrees well with the present 358 observation of dehydrogenation.

359 Diffraction analysis did not immediately indicate this first thermal event of dehydrogenation, 360 because no phase transformations are detected and still only ferrite and the nameless phase are 361 present (cf. Figure 1) at these low temperatures. However, the observation of a sudden change in 362 the sample height, reflected by sudden intensity changes and the need of readjusting the sample 363 as described above, clearly relates to the release of hydrogen. Despite the reproducible and 364 consistent observations of the simultaneous occurrence of the dehydrogenation and the sample 365 height changes at all applied heating rates, thorough understanding of that phenomenon is not yet 366 obtained.

367 In earlier studies of Fe-C coatings [4,9], the exothermic reaction, which clearly relates to 368 dehydrogenation as described above, was also observed, but it was interpreted as the first stage 369 of tempering martensite, where carbon atoms are redistributed resulting in carbon segregation 370 and clustering in an apparent martensite matrix. Although the temperature is similar to the first 371 step of tempering martensite, the release of hydrogen at that temperature as observed in the

372 present work and the missing indication of martensite in the as-deposited coating exclude that the 373 exothermic peak is caused by a redistribution or clustering of carbon. Furthermore, the activation 374 energy for carbon clustering is reported to be significantly higher with about $80 \mathrm{~kJ} / \mathrm{mol}$ [19].

\subsection{Medium temperature range - between $200{ }^{\circ} \mathrm{C}$ and $380{ }^{\circ} \mathrm{C}$}

376 After co-deposited hydrogen from electrolysis during deposition is released (first thermal event), 377 subsequent chemical changes imply the desorption of $\mathrm{CO}_{2}$ at a temperature of about $250{ }^{\circ} \mathrm{C}$ (cf. 378 Figure $2 \mathrm{a}$ ), which indicates the second thermal event. At the same temperature of $250{ }^{\circ} \mathrm{C}$, a 379 previous study on the same as-deposited Fe-C coatings, which however were investigated by in380 situ isochronal annealing after preceding ex-situ isothermal furnace annealing [7], revealed a 381 characteristic desorption of hydrogen. This desorption of hydrogen at $250{ }^{\circ} \mathrm{C}$ is clearly not 382 related to the hydrogen from electrolysis, which was already released during the ex-situ 383 isothermal annealing. The present in-situ analysis could not detect the characteristic desorption 
384 of hydrogen at $250{ }^{\circ} \mathrm{C}$ as part of the second thermal event, due to the ongoing desorption from 385 the first thermal event and a corresponding broad peak of hydrogen evolution in a wide 386 temperature range (cf. Figure 2a). Although the temperature of the second thermal event could 387 not be experimentally determined for a heating rate of $2 \mathrm{~K} / \mathrm{min}$ (cf. Figure 3a), linear regression 388 from the three measured values at higher heating rates (cf. Figure $3 \mathrm{~b}$ ) allowed to calculate the corresponding temperature to amount $250{ }^{\circ} \mathrm{C}$ and the recorded signals for $\mathrm{H}_{2}$ and $\mathrm{CO}_{2}$ support

390 that (cf. Figure 2a). The detected desorption of both $\mathrm{CO}_{2}$ and $\mathrm{H}_{2}$ associated with the second 391 thermal event suggest a relation between hydrogen, oxygen and carbon in the as-deposited 392 coating. The observation that hydrogen still evolves at this temperature indicates that the element 393 is not just present as trapped atoms or molecules in microvoids or grain boundaries (as described 394 above for hydrogen from electrolysis, released in the first thermal event), but additionally 395 constitutes a phase in the as-deposited coating, which is stable up to higher temperature.

396 All the elements involved in the second thermal event are provided by the citric acid in the 397 electrolyte, which seems to promote the incorporation of an additional phase, which is supposed 398 to be an organic compound consisting of carbon, oxygen and hydrogen during electrodeposition 399 and which decomposes at $250^{\circ} \mathrm{C}$. A previous study on as-deposited $\mathrm{Fe}-\mathrm{C}$ coatings revealed by 400 photoelectron spectroscopy that carbon is bound to both hydrogen and oxygen and found that an 401 organic compound is incorporated in the coating in the form of $(\mathrm{COOH})$ [2]. With EDD, this 402 organic phase is not revealed, indicating that it either is not crystalline or of too low volume 403 fraction for measureable diffracted intensities and therefore the present study does not allow an 404 interpretation of the chemical structure of the organic compound. However, the precipitation of 405 magnetite and cementite is a consequence of the decomposition of the organic compound and 406 identified by the in-situ diffraction analysis in the corresponding temperature range. The first 407 presence of an oxide phase, namely magnetite $\mathrm{Fe}_{3} \mathrm{O}_{4}$, is revealed by diffraction analysis at a 408 temperature of $259{ }^{\circ} \mathrm{C}$, hereafter it evolves with increasing temperature. The slow growth rate of 409 magnetite during heating with $2 \mathrm{~K} / \mathrm{min}$, as indicated in Figure 1 by the slowly evolving 410 diffraction intensities for the $\mathrm{Fe}_{3} \mathrm{O}_{4}$ reflection around $34.8 \mathrm{keV}$ at temperatures below $320{ }^{\circ} \mathrm{C}$, 411 could explain the absence of an exothermic peak in DTA for this low heating rate. Together with 412 oxygen used for the formation of oxides, also carbon is provided by the decomposition of the 413 organic compound in the second thermal event and results in the formation of carbides as $\mathrm{Fe}_{3} \mathrm{C}$ at 
$414310^{\circ} \mathrm{C}$ (cf. Figure 1). A relatively small exothermic peak is measured around $310^{\circ} \mathrm{C}$ in the first 415 heating cycle to $1000{ }^{\circ} \mathrm{C}$ by DTA as a shoulder of the exothermic peak related to the third 416 thermal event at $360{ }^{\circ} \mathrm{C}$ (cf. Figure 2a) and suggests a relation the $\mathrm{Fe}_{3} \mathrm{C}$ formation.

417 It is noted that the "nameless phase", which previously was considered an explanation for the 418 location of the measured high concentration of carbon in the as-deposited coatings [4,8,9], still is 419 present at $250^{\circ} \mathrm{C}$ (cf. Figure 1). A previous study further revealed that the as-deposited 420 "nameless phase" is still present even after ex-situ isothermal annealing for $24 \mathrm{~h}$ at $250{ }^{\circ} \mathrm{C}$, thus, 421 it does not decompose with the second thermal event [7] and is not responsible for the formation 422 of magnetite and cementite at this temperature. From the present in-situ study, it is known that 423 the "nameless phase" remains stable up to a temperature of $328^{\circ} \mathrm{C}$.

424 Although missing a clear experimental verification, it has been suggested previously that $\varepsilon / \eta$ $425 \mathrm{Fe}_{2} \mathrm{C}$ transition carbides could be present as minor phase in the otherwise ferritic as-deposited 426 Fe-C coatings $[4,8,9]$, because they would explain the "nameless phase", although the similarity 427 of the two possible carbides, $\varepsilon-\mathrm{Fe}_{2} \mathrm{C}$ and $\eta-\mathrm{Fe}_{2} \mathrm{C}$ [20,21], does not allow their distinction from the 428 present data. Assuming meta-stable $\varepsilon / \eta-\mathrm{Fe}_{2} \mathrm{C}$ in the as-deposited coating, a transformation to $429 \mathrm{Fe}_{3} \mathrm{C}$ would be expected during annealing. The reported enthalpy change and the temperature 430 range of $260^{\circ} \mathrm{C}$ to $350^{\circ} \mathrm{C}$ for that transformation would be associated with an activation energy 431 of $200 \mathrm{~kJ} / \mathrm{mol}$ [19]. For the present Fe-C coatings, such transformation is not indicated by the 432 second thermal event having a much lower activation energy of $98 \mathrm{~kJ} / \mathrm{mol}$. The third thermal 433 event, which occurs at a temperature of $360{ }^{\circ} \mathrm{C}$ with an activation energy of $151 \mathrm{~kJ} / \mathrm{mol}$ is 434 associated with a mass loss and desorption of at least hydrogen (cf. Figure 2a). This rejects that it 435 is related to the transformation of $\mathrm{Fe}_{2} \mathrm{C}$ to $\mathrm{Fe}_{3} \mathrm{C}$ and, thus, questions the presence of $\mathrm{Fe}_{2} \mathrm{C}$ at all.

436 The complementary results from in-situ diffraction analysis and thermal analysis indicate that the 437 disappearance of the "nameless phase" at about $328^{\circ} \mathrm{C} \mathrm{(cf.} \mathrm{Figure} \mathrm{1)} \mathrm{is} \mathrm{related} \mathrm{to} \mathrm{the} \mathrm{third}$ 438 thermal event, which is recorded by a strong exothermic peak with a temperature maximum at $439360{ }^{\circ} \mathrm{C}$. The pronounced release of hydrogen strongly suggests that hydrogen is included in the 440 "nameless phase". This evolution of hydrogen marks the decomposition of the "nameless phase" 441 and, at the same time, explains the abovementioned observation of the sudden change in the 442 sample height during in-situ diffraction analysis in that temperature range (similar to the sample 
443 height changes at low temperature in relation to dehydrogenation during the first thermal event, 444 see above). In addition to hydrogen, to a lesser extent also $\mathrm{O}_{2}$ and $\mathrm{CO}_{2}$ evolve during the third 445 thermal event (cf. Figure 2a), which suggests also oxygen and/or carbon as elements in the 446 "nameless phase". The simultaneous desorption of hydrogen and oxygen indicates that it 447 originates from the family of hydroxides, e.g. ferrihydrite as previously suggested [7].

448 Ferrihydrite is reported as being nanocrystalline with an average domain size of around $2.7 \mathrm{~nm}$ 449 and poor crystallinity [22-24]. The formation of ferrihydrite is known to be favored [25], 450 compared to the more commonly known iron oxides as hematite $\mathrm{Fe}_{2} \mathrm{O}_{3}$ or goethite $\alpha$-FeOOH, in 451 an environment of organic molecules and a high supply of iron. Both of these factors are valid at 452 the coating/electrolyte interface during deposition of the present Fe- $\mathrm{C}$ coating and the formation 453 of metal hydroxides during electrodeposition of different coatings is well known [26]. Although 454 the majority of the electrolyte consists of Fe-ions in their oxidation state $\mathrm{Fe}^{2+}$, the presence of $455 \mathrm{Fe}^{3+}$ being required for the formation of ferrihydrite is likely due to the thermodynamically 456 favored oxidation reaction of $\mathrm{Fe}^{2+}$ to $\mathrm{Fe}^{3+}$ in air. The hexagonal crystal structure of ferrihydrite 457 would even explain some low intensity peaks causing an asymmetry for the $211 \alpha-\mathrm{Fe}$ peak, as 458 previously reported from conventional laboratory XRD [6]. Ferrihydrite has strong adsorptive 459 capacity and a large surface area that acts as a sink for organic matter [24]. This makes the 460 sorption of also carbon-containing species at the surface of ferrihydrite likely and explains that 461 the evolution of all the co-deposited elements (hydrogen oxygen, carbon) is recorded during the 462 third thermal event, thus, with the decomposition of the "nameless phase". The transformation of 463 ferrihydrite into either magnetite or hematite, depends on the environment and access to oxygen 464 [27]. A distinct exothermic peak maximum was reported [27] at about $360{ }^{\circ} \mathrm{C}$ as the thermal 465 transformation of ferrihydrite into magnetite, and an additional transformation can occur at 505 $466{ }^{\circ} \mathrm{C}$ [27], both fit well with the present data. The transformation of ferrihydrite is expected to be 467 non-reversible and it is indeed not observed in the second heating cycle of the Fe-C coating. The 468 corresponding introduction of a name for the yet "nameless phase" certainly is premature and its experimental verification as carbon-associated ferrihydrite is ongoing.

\subsection{High temperature range - above $380^{\circ} \mathrm{C}$}

471 After dehydrogenation of hydrogen from electrolysis (first thermal event) and the release of co-

472 deposited carbon, oxygen and hydrogen by decomposition of both an organic phase (second 
473 thermal event) and the "nameless phase" (third thermal event), the ferrite phase is still present, 474 while magnetite and cementite have formed additionally.

475 A transformation of $\mathrm{Fe}_{3} \mathrm{O}_{4}$ to $\mathrm{FeO}$ was consistently revealed by both diffraction and thermal 476 analysis at a temperature of $570{ }^{\circ} \mathrm{C}$, which fully agrees with thermodynamics. Diffraction 477 analysis at room temperature of a previously annealed sample (not shown here) revealed that $478 \mathrm{FeO}$ still is present after cooling, which is promoted by a rapid cooling rate [28]. This explains 479 the exothermic peak at $295{ }^{\circ} \mathrm{C}$ in the second heating cycle shown in Figure $2 \mathrm{~b}$ as a 480 transformation of still present $\mathrm{FeO}$ into $\mathrm{Fe}_{3} \mathrm{O}_{4}$, which then again transforms to $\mathrm{FeO}$ at higher 481 temperature (interestingly, the second heating cycle, Figure 2b, indicates a temperature of 585 $482{ }^{\circ} \mathrm{C}$, compared to $570{ }^{\circ} \mathrm{C}$ in the first heating cycle, Figure $2 \mathrm{a}$ ).

483 The austenitization temperature measured by DTA and EDD is in good agreement with the 484 theoretical value of $727^{\circ} \mathrm{C}$ for iron-carbon alloys in thermodynamic equilibrium. The diffraction 485 analysis revealed an immediate transformation from $\alpha$-Fe to $\gamma$-Fe without a measurable co486 existence of both phases, which verifies that the actual carbon content of $0.88 \mathrm{wt} \%$ in the Fe-C 487 coatings is close to the eutectoid concentration of $0.76 \mathrm{wt} \%$ for $\mathrm{Fe}-\mathrm{C}$ alloys. The transformation 488 of $\alpha$-Fe into $\gamma$-Fe occurs at the same temperature in the second heating cycle to $1000{ }^{\circ} \mathrm{C}$ as 489 measured by DTA (cf. Figure 2b).

\section{Conclusion}

491 The thermal evolution of electrodeposited Fe-C coatings was investigated systematically during 492 isochronal annealing up to $800{ }^{\circ} \mathrm{C}$ by means of complementary methods of in-situ analysis. With 493 in-situ energy-dispersive synchrotron diffraction, the crystalline phases in the as-deposited 494 coating and the temperature-induced phase transformations were revealed with unique 495 temperature resolution. With in-situ thermal analysis under the same isochronal annealing 496 conditions, the evolution of co-deposited elements and associated mass changes were followed, 497 and this supported the interpretation of the diffraction data and further allowed conclusions on 498 non-crystalline phases. Thus, some method-specific limitations can be disregarded by their 499 complementary use, assuming that the in-situ experiments based on diffraction, 500 thermogravimetric and spectroscopic analysis are carefully carried out with appropriate and 
501 consistent annealing conditions. In the present work, the complementary information from the 502 applied in-situ methods essentially enhanced the understanding of both the as-deposited nature of 503 the Fe-C coatings and their thermal stability.

504 As-deposited Fe-C coatings consist of i) ferrite, ii) a crystalline phase, possibly containing 505 hydrogen, oxygen and iron (previously called the "nameless phase"), iii) a phase containing 506 carbon and most likely also hydrogen and oxygen either being amorphous or constituting a low 507 amount of a crystalline phase and iv) free hydrogen in atomic or molecular form. During 508 annealing, already at low temperature (about $114^{\circ} \mathrm{C}$ ), the free hydrogen is released from the 509 sample (first thermal event). At about $250{ }^{\circ} \mathrm{C}$ (second thermal event), again dehydrogenation 510 occurs, but at the same time also oxygen and carbon redistribute and/or leave the sample, which 511 indicates the decomposition of a phase containing all co-deposited light elements originating 512 from the citric acid used as additive in the electrolyte. At this temperature, the crystalline 513 "nameless" phase still remains unchanged, but decomposes at about $328{ }^{\circ} \mathrm{C}$ (third thermal event) 514 with an associated release of hydrogen and carbon and oxygen from that phase, which 515 subsequently form oxides and carbides at higher annealing temperatures.

516 The results highlight the essential role of the light elements carbon, oxygen and hydrogen, which 517 are co-deposited together with iron. All these elements, thus, not only the intendedly co518 deposited carbon, define the as-deposited state of the Fe-C coatings and rule their overall thermal 519 evolution as well as the associated mechanical properties. The observed temperature-dependent 520 changes provide a useful guide for dedicated post-deposition annealing treatments towards 521 deliberate alterations of the internal structure and associated properties of electrodeposited Fe-C 522 coatings. 


\section{Acknowledgments}

528 The authors kindly acknowledge financial support by OCAS NV, ArcelorMittal Global R\&D

529 Gent (Belgium), a. h. nichro Haardchrom (Denmark) and Fast Track - Societal Partnership

530 (Denmark), funded by the Innovation Fund Denmark (IFD).

531 M. Klaus, D. Apel and C. Genzel from Helmholtz Zentrum für Materialien und Energie (HZME,

532 Germany) are acknowledged for their valuable support during beamtime at the HZB-BESSY II

533 Synchrotron Facility and during subsequent data analysis. Synchrotron diffraction measurements

534 were financially supported by the project CALIPSOplus under the Grant Agreement 730872

535 from the EU Framework Programme for Research and Innovation HORIZON 2020, and by the

536 Danish Natural Science Research Council via Danscatt.

\section{Literature}

540 [1] M. Izaki, H. Enomoto and T. Omi: J. Surf. Fin. Soc. Jpn., 1989, vol. 40, pp. 1304-05.

541 [2] Y. Fujiwara, T. Nagayama, A. Nakae, M. Izaki, H. Enomoto and E. Yamauchi: J.

542 Electrochem. Soc., 1996, vol. 143, pp. 2584-2590.

543 [3] M. Panayotova: Surf. Coat. Technol., 2000, vol. 124, pp. 266-271.

544 [4] A.S.M.A. Haseeb, Y. Hayashi, M. Masuda and M. Arita: Metall. Mater. Trans. B., 2002, 545 vol. 33B, pp. 921-927.

546 [5] T. Müller, J. Grimwood, A. Bachmaier and R. Pippan: Metals, 2018, vol. 8, pp. 363-375.

547 [6] J.O. Nielsen, P. Møller and K. Pantleon: Metall. Mater. Trans. A, 2019, vol. 50A, pp. $548 \quad 3785-3793$.

549 [7] J.O. Nielsen and K. Pantleon: Surf. Eng., 2019, in press (published online, October 2019). 
550 [8] M. Izaki, H. Enomoto, A. Nakae, S. Terada, Y. Eiko and T. Omi: J. Surf- Fin. Soc. Jpn., 1994, vol. 45, pp. 1303-1309.

552 [9] A.S.M.A. Haseeb, M. Arita and Y. Hayashi: J. Mater. Sci., 2001, vol. 6, pp. 4739-4743.

553 [10] M. Schlesinger and M. Paunovic: Electrodeposition of Iron and Iron Alloys, in: M. Izaki (Ed.), Mod. Electroplat., 5th ed., Wiley, 2010, pp. 309-326.

555 [11] Y. Fujiwara, M. Izaki, H. Enomoto and A. Nakae: Denki Kagaku, 1993, vol. 61, pp. 840556 842 .

[12] A.S.M.A. Haseeb and M.Z. Huq: Met. Finish., 1997, vol. 95, pp. 30-34.

[13] N. Fukumuro, S. Kojima, M. Fujino, Y. Mizuta, T. Maruo, S. Yae and Y. Fukai: J. Alloys Compd., 2015, vol. 645, pp. 404-407.

[14] Y. Fujiwara, M. Izaki, H. Enomoto, T. Nagayama, E. Yamauchi and A. Nakae: J. Appl. Electrochem., 1998, vol. 28, pp. 855-862.

[15] M. Izaki and T. Omi: Metall. Mater. Trans. A, 1996, vol. 27A, pp. 483-486.

[16] C. Genzel, I.. A. Denks, J. Gibmeier, M. Klaus and G. Wagener: Nucl. Instruments Methods Phys. Res. A, 2007, vol. 578, pp. 23-33.

[17] E.J. Mittemeijer: J. Mater. Sci., 1992, vol. 27, pp. 3977-3987.

[18] W.Y. Choo and J.Y. Lee: Metall. Trans. A, 1982, vol. 13A, pp. 135-140.

[19] L. Cheng, C.M. Brakman, B.M. Korevaar and E.J. Mittemeijer: Metall. Trans. A, 1988, vol. 19A, pp. 2415-2426.

[20] H.K.D.H. Bhadeshia: Carbide precipitation, in: Bainite Steels Theory Pract., 3rd ed., Maney Publishing, 2015, pp. 61-86.

571 [21] H.L. Yakel: Int. Met. Rev., 1985, vol. 30, pp. 17-40. 
572 [22] U. Schwertmann and W.R. Fischer: Geoderma., 1973, vol. 10, pp. 237-247.

573 [23] E. Jansen, A. Kyek, W. Schäfer and U. Schwertmann: Appl. Phys. A, 2002, vol. 74, pp. $574 \quad 1004-1006$.

575 [24] S. Das, M.J. Hendry and J. Essilfie-Dughan: Environ. Sci. Technol., 2010, vol. 45, pp. $576 \quad 268-275$.

577 [25] R.M. Cornell and U. Schewertmann: Soils, in: Iron Oxides Struct. Prop. React. Occur. Uses., 2nd ed., Wiley, 2003, pp. 433-468.

579 [26] M. Panunovic and M. Schlesinger: Electroless deposition, in: Fundam. Electrochem. Depos., Wiley, 2006, pp. 139-168.

581 [27] A.S. Campbell, U. Schwertmann and P.A. Campbell: Clay Miner., 1997, vol. 32 , pp. $615-622$.

583 [28] X. Yu, Z. Jiang, J. Zhao, D. Wei and C. Zhou: Appl. Mech. Mater., 2013, vol. 395-396, $584 \quad$ pp. 273-278. 